\title{
Zambia: Poverty Reduction Strategy Paper-Joint Staff Advisory Note
}

The attached Joint Staff Advisory Note (JSAN) of the Poverty Reduction Strategy Paper Progress Report for Zambia, prepared jointly by the staffs of the World Bank and the IMF, was distributed with the member country's Poverty Reduction Strategy Paper (PRSP) to the Executive Boards of the two institutions. The objective of the JSAN is to provide focused, frank, and constructive feedback to the country on progress in implementing its Poverty Reduction Strategy (PRS).

To assist the IMF in evaluating the publication policy, reader comments are invited and may be sent by e-mail to publicationpolicy@imf.org.

Copies of this report are available to the public from

International Monetary Fund • Publication Services $70019^{\text {th }}$ Street, N.W. • Washington, D.C. 20431

Telephone: (202) 623-7430 • Telefax: (202) 623-7201

E-mail: publications@imf.org•Internet: http://www.imf.org

\section{International Monetary Fund Washington, D.C.}





\section{INTERNATIONAL DEVELOPMENT ASSOCIATION \\ AND \\ INTERNATIONAL MONETARY FUND}

REPUBLIC OF ZAMBIA

\section{JOINT IDA-IMF STAFF ADVISORY NOTE ON THE POVERTy Reduction STRATEgy PAPER (FifTh National DevelopMent Plan - FNDP)}

Prepared by the Staffs of the International Development Association (IDA) and the International Monetary Fund (IMF)

Approved by Obiageli K. Ezekwesili (IDA) and Saul Lizondo and Matthew Fisher (IMF)

July 11,2007

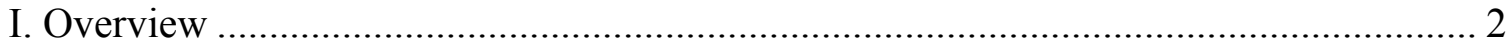

II. Participatory Process ............................................................................................. 2

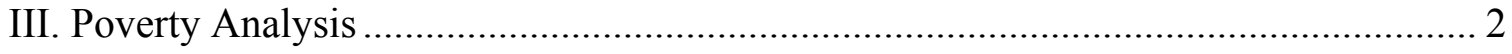

IV. Achieving the Goals of the FNDP ........................................................................ 3

A. Macroeconomic Policy Framework and FNDP Financing Scenarios ................. 3

B. Policies for Growth and Investment ............................................................. 5

C. Human Development and Service Delivery .............................................. 7

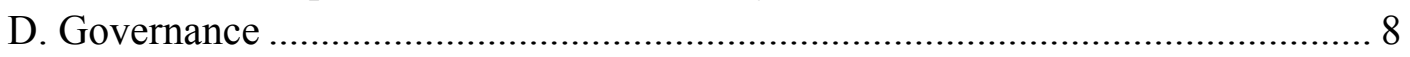

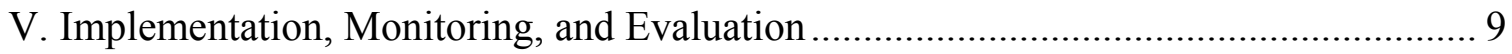

VI. Conclusions and Issues for Discussion............................................................ 9 


\section{OVERVIEW}

1. The Government of the Republic of Zambia has officially launched its second Poverty Reduction Strategy Paper, known as the Fifth National Development Plan (FNDP) for the period 2006-10. ${ }^{1}$ The FNDP is guided by the National Vision 2030 (NV2030), which has as its goal to transform Zambia into "a prosperous middle-income country by the year 2030." It is organized around the theme of "broad-based wealth and job creation through citizenry participation and technological advancement" and it focuses on "economic infrastructure and human resources development."

2. The FNDP is a marked improvement on the previous PRSP. The FNDP builds upon the achievements of the first PRSP, for example, strong improvements in macroeconomic performance and progress in public expenditure management. It has strengthened its focus on the key issues, emphasizes achieving tangible results, and includes appropriate monitoring and evaluation arrangements. The theme of broad-based growth is analyzed from several angles and in sufficient detail. On policies, it appropriately places emphasis on the importance of a stable macroeconomic framework, improved domestic revenue collection, good governance, increased production and productivity in agriculture, and strengthened human resource development. One marked improvement is that it presents an elaborate medium-term expenditure framework (MTEF) under which the external cooperating partners are requested to provide predictable assistance either through direct budget support or sector wide approaches (SWAP). This policy is intended to achieve a gradual move away from the traditional individual project mode of providing assistance.

\section{Participatory Process}

3. Preparation of the FNDP was highly participatory. All the major stakeholderscivil society, cooperating partners, the private sector, permanent secretaries, members of parliament and the cabinet - were involved in the preparation of the document. Priorities were arrived at through a series of Sector Advisory Working Groups (SAG) meetings and the draft and its implications were discussed at a stakeholder meeting. The consultative process integrated the views of 21 SAGs and included the preparation of 72 district development plans that were approved by the respective Provincial and District Development Coordinating Committees. As a consequence, the FNDP has a high degree of ownership compared to the previous PRSP.

\section{Poverty Analysis}

4. Staffs commend the authorities for the critical review of poverty dynamics in Zambia, which informed its poverty reduction strategy. The FNDP acknowledges that despite the implementation of the PRSP and positive economic growth since 1999, national

\footnotetext{
${ }^{1}$ The first Zambia PRSP initially covered the period 2002-04 and was later extended to include 2005.
} 
poverty levels remain high. ${ }^{2}$ Between 1998 and 2004, the national incidence of poverty fell from 73 percent to 68 percent and extreme poverty - the population living below US\$1 per day-fell from 58 percent to 53 percent. The FNDP also acknowledges that the degree of poverty and its severity is more pronounced in the rural areas; that the gender gap remains significant; and that Zambia's income distribution inequality still remains high - the Gini coefficient was 0.57 in 2004, down from 0.66 in 1998. The FNDP also discusses, although less comprehensively, the non-income aspects of poverty. It recognizes that better quality and timely data on poverty is needed to strengthen poverty analysis.

\section{ACHIEVING THE GOALS OF THE FNDP}

\section{A. Macroeconomic Policy Framework and FNDP Financing Scenarios}

5. Notwithstanding the strengthening in macroeconomic performance in recent years, the FNDP rightly acknowledges that fiscal and monetary policy at times fell short of objectives. The FNDP reviews the significant improvement in macroeconomic performance in recent years and emphasizes that more prudent spending policies have allowed the gradual lowering of domestic financing of the budget. These together with the extensive external debt relief received through the HIPC Initiative and MDRI have quickly reduced debt service payments, thus providing scope for additional poverty reducing spending. Achieving monetary control has, however, proved problematic at times mainly owing to inadequate instruments to mop up excess liquidity and the Bank of Zambia's limited operational autonomy. Also, lack of coordination of fiscal and monetary policies has further hampered liquidity management.

6. The macroeconomic strategy of the FNDP is to build on previous achievements by maintaining fiscal and financial stability and deepening structural reforms. The overarching objective of the FNDP is to accelerate growth to an average of at least 7 percent per year, which is broadly in line with the medium-term outlook in Zambia's PRGF. ${ }^{3} \mathrm{~A}$ related goal is to broaden the sources of growth to enhance its poverty reducing impact. The FNDP recognizes that key to the attainment of these objectives are continued macroeconomic stability, and improved competitiveness and diversification through the implementation of the Private Sector Development (PSD) program that draws, inter alia, on the findings of the 2005 Diagnostic Trade Integration Study, the Financial Sector Development Plan (FSDP), and the National Agriculture Policy, complemented by accelerated infrastructure investments.

\section{The FNDP acknowledges the need to strengthen fiscal and monetary policy implementation in order to maintain macroeconomic stability.}

\footnotetext{
2 The latest available poverty data are for 2004 and thus do not reflect the impact on poverty of the strong economic growth registered in 2005 and 2006.

${ }^{3}$ More ambitious projections for growth and the medium term resource envelope are presented in an alternative scenario.
} 
- $\quad$ Regarding fiscal policy, the FNDP appropriately identifies the need to improve budget execution, strengthen financial accountability and expenditure monitoring, and enhance the revenue base. The strategy correctly identifies broadening of the tax base and rationalization of the structure of tax rates as key principles that should underlie tax reforms. However, the revenue measures announced in the 2007 budget, particularly the granting of wide-ranging tax incentives for investment, appear inconsistent with these key principles and could jeopardize FNDP targets for the medium-term resource envelope.

- $\quad$ Regarding monetary policy, the FNDP acknowledges that excessive monetary growth has been a major contributor to high inflation in Zambia. The FNDP rightly points to the need to strengthen the coordination between the Ministry of Finance and the Bank of Zambia with regard to cash and treasury management. It also states that the operational autonomy of the Bank of Zambia will be reinforced, based on the reform plan set out in the Financial Sector Development Plan (FSDP). The overall monetary policy objective rightly focus on achieving and maintaining single-digit inflation during the period of the plan.

\section{Staffs support the authorities' plans to formulate a comprehensive debt} management strategy. A key component of the macroeconomic strategy is to contain domestic debt and the amount of public resources spent on debt service. The FNDP also underlines that external borrowing will continue to be on highly concessional terms that are consistent with the country's repayment capacity.

9. While the FNDP is cognizant of the vulnerabilities of the Zambian economy, the discussion of risks could be strengthened. The FNDP identifies the failure of scaling up of aid as a particular risk to the Zambian economy, but is less specific on other important potential risks, such as a sharp fall in copper prices and drought. The FNDP's emphasis on diversifying the production base is, however, appropriate to address the main risks the Zambian economy is facing.

\section{The FNDP should explain in greater detail how the existing financing gap is}

expected to be closed. The Government has sought to cost and identify financing for the various elements of the FNDP. In the baseline scenario, which assumes continuation of existing tax policies and donor financing according to existing commitments, there is a financing gap of about 5 percent of the FNDP's total cost or 1.4 percent of GDP per year. The FNDP is sufficiently prioritized to allow for flexible adjustment of expenditure if the financing gap is not closed. The resource gap under a growth scenario more in line with the attainment of the MDGS would be substantially higher. While the Government recently has taken steps to increase domestic tax revenues by reforming the fiscal regime of the mining sector, the revenue impact over the FNDP implementation period remain uncertain. Staffs recommend that the Government seeks assurances from cooperating partners on their ability 
to scale up aid and proceed expeditiously with the implementation of the proposed changes to the fiscal regime for the mining sector.

\section{B. Policies for Growth and Investment}

\section{The linkage between growth and poverty reduction has been weak. Despite} posting the longest spell of positive growth (since 1999) in Zambia's post-independence period and a representative reduction in poverty, the perception among Zambian citizens is that poverty reduction can be accelerated. One reason for this view is that much of the growth has been concentrated in the largely urban-based and capital-intensive sectors of mining, wholesale and retail trade, and construction. While the FNDP recognizes the importance of continued contributions of the mining, construction and energy sectors to overall growth, its major focus is on the sectors with direct pro-poor growth impact through increased employment and income opportunities for the poor. These include rural development, agriculture, tourism, and the manufacturing sectors.

\section{While pursuing policies to enhance the impact of growth on poverty, it is} important to assess the consequences for the environment. Even though the FNDP recognizes the causes leading to environmental and natural resource degradation, the analysis on how to solve such problems could be strengthened. In staffs' view, this requires an effort to mainstream sustainable development across line ministries and a concerted effort to collect information on natural resource management and environmental degradation to guide future decisions in this area.

\section{The FNDP guides to a large extent the allocation and use of resources using the} MTEF process and the annual budget. For example, the FNDP aims to increase the share of the budget devoted to agriculture from 5 percent in 2006 to 9 percent in 2010 as a means of reducing the high incidence of poverty in the rural sector. Staffs are concerned that the planned increase in spending on the agricultural sector may not always allocate sufficient funds to those programs that are known to contribute to improved agricultural productivity such as agricultural research, technological and irrigation development, and diversification in the production of both staple and cash crops to ensure food security. Therefore, a major challenge that needs urgent resolution concerns the subsidized fertilizer support program that absorbs significant resources but is not well targeted as it reaches less than 10 percent of intended beneficiaries (i.e., small-scale farmers) and crowds out programs that could enhance the sector's productivity in a more sustainable manner.

\section{Strengthening economic infrastructure is one of the critical elements of the} FNDP. The FNDP acknowledges that poor physical infrastructure such as roads, electricity, irrigation, and water and sanitation has been one of the major bottlenecks holding back private sector development in the country. Staffs would advice the authorities to be mindful of the needs to upgrade and expand rail and energy infrastructure as well as 
telecommunications as all these play an important role in reducing the cost of doing business in Zambia.

15. The FNDP recognizes that the public purse cannot undertake all the investments needed and has identified public private partnerships as an important mechanism to realize these investments. In many utility sectors, however, tariffs are not set such that they cover full costs or are set in a manner that they decrease competitiveness or favor a particular sector. ${ }^{4}$ In addition, arrears between government agencies and utilities continue to cause difficulty within the sector. Staffs urge the Government to pay its bills on time and rebalance tariffs in the utility sector such that they reflect full cost, attract investors, and allow for increased access to electricity and water and sanitation services and improve Zambia's competitiveness.

16. The Private Sector Development (PSD) initiative, including Zambia's Financial Sector Development Program (FSDP), articulates many of the key measures needed to create a better business environment and investment climate in Zambia. The concern is, therefore, with implementation, as progress under both the PSD initiative and the FSDP has been slow. For example, ease of trading across Zambia's borders continues to rank in the bottom deciles of countries in the "Doing Business" indicators, the license fee for an international telecommunications gateway remains prohibitively high, while the resolution of insolvent nonbank financial institutions has faced repeated delays and overall access to the financing system is low, with fewer that 15 percent of Zambians holding a bank account. The staffs concur that improved implementation of the PSD and the FSDP, as emphasized in the 2007 budget speech, is essential if the growth objectives of the FNDP are to be realized.

\section{The mining sector has driven economic development in Zambia for over}

70 years. The FNDP discusses various constraints to the development of large and small scale mining and the need to improve its domestic backward and forward linkages. From the dismal condition in which it found itself at the beginning of this millennium, the mining sector has recovered because of large investments and favorable global market conditions. Staffs commend the Government for taking steps to reform the fiscal regime of the mining sector while preserving Zambia as a competitive, credible, and attractive investment destination, but advocate the inclusion of an additional revenue-sharing mechanism that would capture a higher share of mineral rents for government during period of abnormally high international prices for minerals. Such a device is currently not part of the proposed reforms. With the expected increase in fiscal gains from the boom in copper exports, the authorities are urged to ensure transparent management of these resources. In this regard, Zambia's intention to join the Extractive Industry Transparency Initiative, which supports

\footnotetext{
${ }^{4}$ In the telecom sector, local fixed-line rates are kept low and as such are cross subsidized by high international rates. In the electricity sector, tariffs for the mining sector are set below cost and hence are subsidized by households and other economic sectors, amounting to an estimated US\$20 million for 2006. In the water sector, tariffs do not cover the cost of new investments and therefore do not promote expansion of the network of water pipes.
} 
improved governance in resource-rich countries through the verification and full publication of company payments and government revenues from oil, gas, and mining, is a welcome first step.

\section{Human Development and Service Delivery}

18. The FNDP correctly acknowledges that spending on health and education in addition to improving health and social welfare is important for achieving sustainable growth. This is particularly the case in a country with a high incidence of Malaria, high prevalence rates of HIV/AIDS, and a shortage of skilled manpower. The FNDP discusses frankly the challenges in the social sectors.

19. The FNDP acknowledges some of the achievements in basic education such as increased enrolment and a better gender balance but also notes that the quality of education needs further improvements. In addition, secondary and tertiary education has, hitherto, not been priority segments of the educational system and in the last 30 years, there has been little investment in secondary and tertiary education. Zambia's educational system continues to be characterized by low transition rates between the three different levels. Since the FNDP places a premium on skills development, issues of intra-education (i.e. at different levels of the educational system) efficient resource allocation remain a major challenge. Staffs are concerned that the FNDP's strategy for the education sector could prove difficult to implement due to existing constraints on resources. In comparison, formulating sub-sector specific objectives, strategies and targets would allow for such alignment of resources and provide comfort for a much needed increase in resource flows to the sector as to escape the "low cost, low quality" system currently in place.

20. The FNDP admits that progress in health indicators has been stagnant under the previous PRSP. The FNDP rightly highlights the current human resources crisis in the health sector, but the outlined strategy is too focused on the number of health workers and training. Although staffs concur that these issues are important, the results of the recent public expenditure tracking survey shows that significant gains can be made by improving productivity of health workers and address tardiness and absenteeism. To improve the availability of essential drugs and medical supplies a stronger collaboration between the Ministry of Health $(\mathrm{MoH})$ and the Ministry of Finance and National Planning on budget planning and procurement is needed, as the actual availability of funds are not timed well to guarantee the procurement of essential drugs, resulting in stock outs. Furthermore, the lack of consumption data and the fragmentation of the supply chain management results in poor forecasting and planning. A logistic management information system and capacity building at district level can address this problem.

21. In addition, there is a need to urgently address the deficiencies in the health sector's capital assets, that is, health infrastructure, utilities, and equipment. For example, less than half of Regional Hospital Centers (RHCs) have an electric connection, 
high rates of nonfunctional utilities and transport equipment erode access to RHCs, and many hospitals continue to lack appropriate medical equipment.

22. It is clear that Zambia is one of the countries worst affected by malaria and HIV/AIDS. There is no aspect of life that is not directly or indirectly affected by these diseases. The malaria and HIV/AIDS programs are very strongly focused on increasing access to drug treatment. The importance of drug treatment and their availability is apparent. However, staffs recommend that the Government continues its efforts to stop the further spread of HIV/AIDS and malaria through effective and widespread prevention efforts. The direct involvement of communities in prevention, treatment, and care activities has proven to be a highly effective strategy.

\section{Mainstreaming of gender in Zambia's development programs has been} challenging and the importance for the development process is not always well understood. As a result, progress in implementing the national gender policy, adopted in 2000 has been limited. For example, illiteracy levels remain significantly higher among women at 75 percent compared to men at 65 percent. To strengthen implementation a strategic action plan (2005) was developed and the cabinet office has taken on the role of coordinating, and monitoring and evaluating the activities identified. Furthermore, additional institutional structures have been put in place in line ministries and at the district and provincial levels. Staffs agree that this bodes well for implementation of the strategy and its action plan. However, due to the persistence of deep gender inequalities and disparities, the FNDP could promote stronger accountability mechanisms for promotion of gender equality and measures to strengthen collection of gender-specific economic data.

\section{Governance}

24. The FNDP's governance priority is to improve and institutionalize political, administrative, financial, and budgetary transparency and accountability in all priority sectors and programs. The FNDP's governance goals include: improving access to justice; upholding human rights; improving the management of free and fair elections; strengthening collaboration and cooperation among governance institutions; improving the National Assembly's oversight role over the Government; enhancing constitutionalism and rule of law; and institutionalizing anti-corruption programs in all public institutions by 2010 . Staffs commend the authorities for its recent successes in its fight against corruption, as witnessed by the positive conclusions of the Zamtrop and Bulaya cases, and encourage the adoption of the National Anti-Corruption Policy and Strategy and resolve the future of the Task Force on Corruption as these are important actions that signal an unwavering commitment to fight corruption.

25. The Republican Constitution that is currently undergoing review is expected to be finalized during the plan period. There are certain proposed amendments - such as those that would put the public sector pension fund on sound financial footing and the 
amendment to change the budget cycle to allow for parliamentary approval of the budget before the start of its fiscal year - that seem uncontroversial. Given the importance of these revisions, if possible, ways should be found to de-link them from the wider constitutional reform process, which could take several years.

26. Most of the governance-related reform initiatives have progressed beyond planning and are under implementation, including the Public Expenditure and Financial Management Reform Program PEMFA, Public Service Management (PSM), and Local Government Development Program (LGDP). The Government has finalized its decentralization policy and efforts are underway to design an inter-governmental fiscal architecture (IFA) that would help effect fiscal decentralization. Staffs encourage accelerated implementation of the ongoing reform effort, as these reforms, in particular those that strengthen institutional capacity, are critical to the successful implementation of the FNDP.

\section{ImPlementation, Monitoring, AND Evaluation}

27. The importance of institutional frameworks for implementation, monitoring and evaluation are acknowledged and prioritized by the FNDP. The newly created Planning Division (PEMD) of the Ministry of Finance will be the focal point for institutional linkages and to institutionalize five year development planning as the means to guide the budget preparation process. Staffs recommend that the Government review the existing regulatory and legislative systems for planning and budgeting in order to streamline this process. This should include the role of parliament in the planning and budget processes, as well as the coordination between Cabinet Office and the Ministry of Finance and National Planning.

28. Although the FNDP is a results-based strategy that focuses on agreed targets and results, its key performance indicators (KPI) tables are not clearly linked to its povertyimpact indicators. With the formal creation of the Monitoring and Evaluation Unit under PEMD during the implementation of the first PRSP, the Plan seeks to institutionalize a system to monitor inputs, outputs, outcomes, and impacts so that resources are strategically managed and progress tracked. In particular, monitoring and evaluation process will provide essential data and insights for drawing lessons, priority setting and informed review of the FNDP implementation. The monitoring system will also include process indicators that are related to the implementation of the FNDP at both the macro and sectoral levels. Such indicators will be closely linked to the performance assessment framework (PAF) that is currently used in the context of direct budget support. Staffs concur with the importance of such a system and urges Government to finalize it as a soon as possible.

\section{CONCLUSIONS AND ISSUES FOR Discussion}

29. Staffs consider that the FNDP broadly provides a comprehensive framework for growth and poverty reduction in Zambia. Without a scaling up of donor assistance, and/or inability to raise domestic revenues there will be a significant shortfall of resources to implement the plan. The Government should continue to base its MTEF and subsequently its 
annual budget on realistic financing assumptions. Areas that the Government should focus on to improve its ability to implement the FNDP include: (i) putting in place a more efficient, productive, and equitable tax system covering all sectors; (ii) consistently using the FNDP to guide expenditure allocations; (iii) improving its capacity to evaluate the effectiveness and efficiency of expenditure programs as a means to be able to rank new and ongoing expenditure programs by their impact on growth and poverty reduction; (iv) improving incentives to service delivery at all levels of government; (v) speeding up the implementation of the reforms in the Private Sector Development initiative to improve Zambia's competitiveness; and (vi) rebalancing utility tariffs such that they cover all costs in conjunction with putting in place a framework for Public Private Partnership that could assist with the needed resource mobilization.

30. The main risks relate to lower-than-expected economic growth and shortfalls of external financing. Macroeconomic stability and growth could come under pressure from volatility in the world market price for copper. Further, lack of tangible progress in improving Zambia's investment climate could endanger diversification and reduce investments in productivity enhancing activities. The FNDP's baseline financing scenario contains a significant financing gap that is expected to be filled by a combination of higher domestic tax revenues and larger external inflows. The maintenance of sound macroeconomic policies and continued implementation of economic reforms are key to attract larger inflows from donors. The Government and cooperating partners have embarked on a harmonization agenda and continued commitment by all partners to the agreed processes in the Joint Assistance Strategy for Zambia (JASZ) ${ }^{5}$ will be important as well to improve the coordination and effectiveness of the aid.

\section{Do Directors concur with the areas identified by staffs as key for:}

- $\quad$ sustaining growth and reducing poverty, particularly the need to implement PSD and agriculture related reforms, improve infrastructure, and address the human resource crisis in the social sectors?

- $\quad$ strengthening implementation of the FNDP, particularly by increasing domestic tax revenue, and improving the efficient use of public resources, while strengthening the incentives for public service delivery, and managing the difficulties posed by capacity weaknesses, governance, and natural resource dependency?

\footnotetext{
${ }^{5}$ The JASZ has been prepared in collaboration with the Government and twelve bilateral donors together with the African Development Bank, The World Bank, the European Commission and the United Nations system are signatories to the JASZ.
} 